\title{
THE POSTNATAL REDUCTION OF THE UNCROSSED PROJECTION FROM THE NASAL RETINA IN THE CAT ${ }^{1}$
}

\author{
D. S. JACOBS, ${ }^{*}$ V. H. PERRY, $\ddagger$ AND M. J. HAWKEN ${ }^{* 2}$ \\ * University Laboratory of Physiology, University of Oxford, Parks Road, Oxford OX1 3PT and $\ddagger$ Department of Experimental \\ Psychology, South Parks Road, University of Oxford, Oxford OX1 3UD, United Kingdom
}

Received August 19, 1983; Revised March 21, 1984; Accepted March 21, 1984

\begin{abstract}
We have investigated the postnatal reduction of the uncrossed projection from the nasal retina in the cat by injecting horseradish peroxidase into one optic tract of kittens and cats and retrogradely labeling the cells in the ipsilateral retina that have an uncrossed projection to the brain. The newborn kitten has over 600 uncrossed cells in the nasal retina. The number is reduced to about one-quarter of that value by postnatal day 10 . The two adult cats examined had 75 and 100 of these ipsilaterally projecting nasal cells. They are distributed all across the nasal retina, and most have the morphology characteristic of gamma cells.

A lesion in one optic tract in the newborn kitten results in an increase in the number of cells from the nasal retina with an ipsilateral projection at maturity. There are more of these cells in the region that has been depleted of ganglion cells by the lesion. This excess consists mostly of gamma and epsilon cells. These findings indicate that competitive factors play a role in the elimination of inappropriate ganglion cell projections in the cat, and that this process contributes to the precision of the nasotemporal division of the retina.
\end{abstract}

The visual system of the cat, like those of primates and other carnivores, is characterized by a large binocular visual field, high visual acuity, and partial decussation at the optic chiasm. Partial decussation, according to the classical theory (Polyak, 1957), involves the exchange of fibers between the right and left optic nerves, at the optic chiasm, in such a way that the right hemisphere receives input from those retinal ganglion cells of both eyes that subtend the left visual hemifield, and the left side of the brain receives input from those retinal ganglion cells of both eyes that subtend the right visual hemifield. The degree of partial decussation is correlated with the extent of frontal positioning of the eyes (Gudden's law, from Walls, 1942).

The cat's retinal projection is characterized by this classical pattern of decussation, with two exceptions (Stone, 1966). There is a zone of overlap at the vertical meridian consisting of some ganglion cells that project to one hemisphere and some ganglion cells that project to the other, and there is a population of cells temporal to the vertical meridian with a contralateral projection to the brain.

Anatomical studies using the retrograde transport of horseradish peroxidase (HRP) (Leventhal et al., 1980; Wässle and Illing, 1980; Illing and Wässle, 1981) have subsequently revealed that the major morphological classes of ganglion cells, alpha, beta, gamma (Boycott and Wässle, 1974), and epsilon (Leventhal et al., 1980), have different decussation patterns

\footnotetext{
${ }^{1}$ This research was supported by Medical Research Council Grant G979/49 to C. Blakemore. D. S. J. was supported by a scholarship from the Rhodes Trust. V. H. P. is a Locke Fellow of the Royal Society.

${ }^{2}$ To whom all correspondence should be addressed.
}

and that the crossed projection from the temporal retina is comprised mostly of gamma cells and some alpha cells. The physiological classes, $\mathrm{Y}, \mathrm{X}$, and $\mathrm{W}$, of retinal ganglion cells (Enroth-Cugell and Robson, 1966; Cleland et al., 1971; Stone and Hoffman, 1972) that probably correspond to the morphological classes, alpha, beta, and gamma, show the same pattern of decussation (Fukuda and Stone, 1974; Stone and Fukuda, 1974; Kirk et al., 1976a, b). The epsilon cells are probably the morphological counterparts of a subclass of $\mathrm{W}$ cells. These anatomical and physiological studies have also shown that the projection sites of these classes are different and that the cell types that adhere less to the classical concept of decussation at the chiasm project to termination sites in the midbrain as opposed to the thalamus.

It is only recently that attention has been directed to the prenatal development of partial decussation in the kitten. By embryological day 30 (E30) an optic chiasm is present and the crossed projection is, at this time, greater than the uncrossed projection (Anker, 1977). Throughout the remaining prenatal period the crossed projection continues to be greater and more advanced than the uncrossed projection (Shatz, 1983). Furthermore, Walsh et al. (1983) have recently shown that the different morphological classes of ganglion cells have different birth dates, resulting in a sequential ventrolateral displacement of the axons of each class in the optic tract (Torrealba et al., 1982). They also found that the later the birth date of a particular cell type, the greater the proportion of cells of that type in the temporal retina which project contralaterally.

We have used the retrograde transport of HRP to investigate the precision of the uncrossed projection during postnatal development in the cat. A preliminary report of some of these results has been presented elsewhere (Jacobs and Perry, 1983). 


\section{Materials and Methods}

Developmental series of postnatal kittens-HRP injections. Pressure injections of HRP were made into one optic tract in nine kittens. In this study, the first $24 \mathrm{hr}$ after birth are designated postnatal day 1 (P1). Three kittens were injected on P1, four on P4, and two on P10. The kittens were anesthetized with 1 to $3 \%$ halothane in $\mathrm{O}_{2}$ and placed in a stereotaxic frame modified to provide a continuous supply of anesthetic (Eldridge et al., 1981) during the surgery and injection. A small incision was made in the scalp, and the surrounding skin was injected with long-lasting local anesthetic.

The injection site, which was the left optic tract at the level of the lateral geniculate nucleus (LGN), was determined stereotaxically (Rose and Goodfellow, 1973) and from landmarks on the skull and brain. For each kitten, two pressure injections were made 1 to $2 \mathrm{~mm}$ apart in a single parasagittal plane using a Hamilton syringe. Each injection consisted of multiple small injections, through the depth of the LGN and optic tract, of either 50\% HRP (Boehringer/Mannheim) in 2\% dimethylsulfoxide or $20 \%$ wheat germ agglutinin-HRP in distilled water, totaling 0.5 to $1 \mu \mathrm{l}$, delivered over at least $20 \mathrm{~min}$. The needle was allowed to remain in place for at least an additional $5 \mathrm{~min}$ before being raised out of the brain.

The scalp was sutured, and after recovery from anesthesia, the kitten was returned to its mother.

Optic tract lesions in P1 kittens. The same method as for HRP injection was used for making a lesion in the optic tracts of five P1 kittens, except that instead of a Hamilton syringe, an electrode (tip diameter $0.7 \mathrm{~mm}$ ) was lowered into the right instead of the left hemisphere, and a lesion was made by using a radiofrequency source to bring the brain tissue up to $70^{\circ} \mathrm{C}$ for $1 \mathrm{~min}$.

Adult cats-HRP injections. The five kittens that received lesions and the two controls were allowed to grow to at least $900 \mathrm{gm}$. Anesthesia was induced with ketamine and maintained intravenously with $\mathrm{Al}$ thesin; the skin surrounding the incision was injected with local anesthetic. The extent of the LGN was determined electrophysiologically by reference to the topographic maps of Sanderson (1971). Four to six injections of HRP solution $(0.5$ to $1 \mu \mathrm{l})$ each were then distributed along two parasagittal planes, using the same injection protocol for each injection as for the kittens in the developmental series. After the injections the scalp incision was sutured, and the cat recovered from anesthesia.

Tissue processing. Twenty-three to $26 \mathrm{hr}$ after the last injection, the animals were deeply anesthetized with barbiturate (Sagatal) and perfused through the heart with $0.9 \%$ saline followed by fixative consisting of $2 \%$ glutaraldehyde and $1 \%$ paraformaldehyde in $0.1 \mathrm{M}$ phosphate buffer, $\mathrm{pH} 7.2$. The eyes were enucleated after 3 to $5 \mathrm{~min}$ of perfusion with fixative. The retinas were dissected, postfixed, reacted to demonstrate HRP with a modified Hanker-Yates protocol, and mounted on gelatinized slides (Perry and Linden, 1982). Retinas from the cats that received lesions and from one of the control animals were counterstained with cresyl violet before dehydration. All retinas were drawn before and after processing, to allow determination of shrinkage.

The brain was removed from the skull after fixation and was immersed in $30 \%$ buffered sucrose until it sank. Coronal sections $50 \mu \mathrm{m}$ thick were cut on a freezing microtome, and the fourth and fifth of every five sections were saved. The two series were mounted separately on gelatinized slides; one series was stained with cresyl violet and the other reacted for HRP using the same protocol as for the retinas.

Analysis. The retinas ipsilateral to the HRP injections were drawn at a magnification of $\times 10$ and the position of each labeled cell in the nasal retina was marked using an X-Y plotter coupled to a microscope stage. The retinas were scanned from the nasal boundary of the temporal hemiretina to the nasal periphery using a $\times 40$ objective lens and an eyepiece graticule $(240 \times 240 \mu \mathrm{m})$. In all of the kittens, there was an obvious border beyond which there were only scattered uncrossed cells. So as not to confound the plot with scatter at the border, which might differ with age, no labeled cell was marked that was less than $120 \mu \mathrm{m}$ in the nasal direction from the border. The cell bodies of all of the labeled cells in the nasal retina of the two normal cats and one cat that received a lesion were drawn at a magnification of $\times 400$, and the soma areas were measured using a digitizing drawing pad.

Double label experiments. Experiments using the retrograde transport of two tracers were undertaken to reveal whether there are retinal ganglion cells in the kitten with axons that branch at the optic chiasm. Four kittens were used in this study. The same injection procedure was used as for HRP injections, except that a second pair of injections of $5 \%$ Fast Blue (FB) (Bentivoglio et al., 1980) in $0.9 \%$ saline was made in the other optic tract. Three kittens were injected at P1 and the fourth at $\mathrm{P} 2$. Two of the $\mathrm{P} 1$ kittens survived 23 to $26 \mathrm{hr}$; the remaining $\mathrm{P} 1$ kitten and the P2 kitten survived 48 to $56 \mathrm{hr}$.

Tissue processing was the same as described previously for HRP
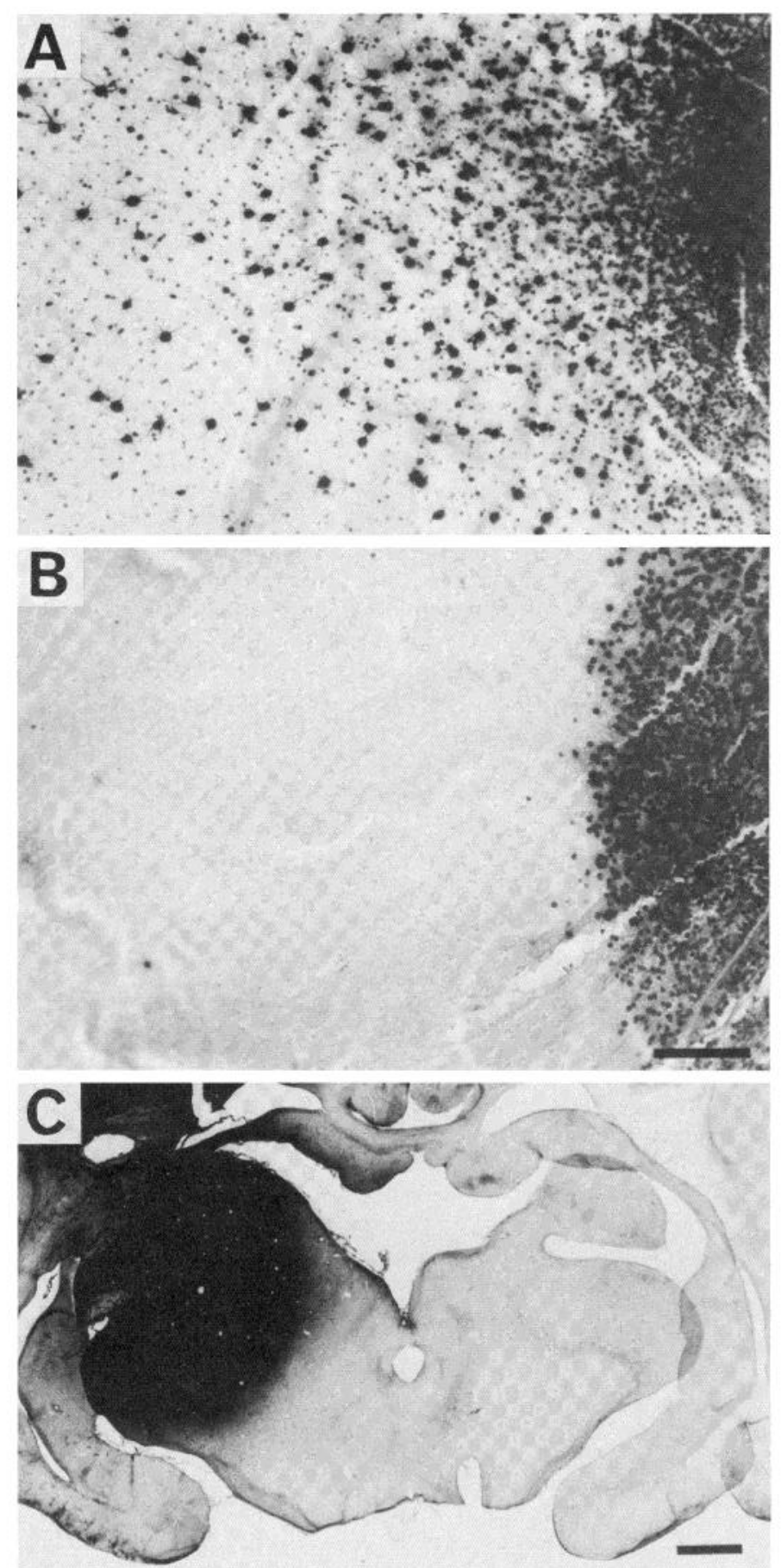

Figure 1. The retinal borders of the crossed and uncrossed projections to the brain, in the adult cat, as demonstrated by the retrograde transport of HRP. The retinal region photographed is the inferior part of the area centralis. The injections were made into the left hemisphere. $A$, The retina contralateral to the injection site demonstrating the retinal extent of the crossed projection in the adult. $B$, The retina ipsilateral to the injection site, demonstrating the retinal extent of the uncrossed projection in the adult. Scale bar $=250 \mu \mathrm{m}$. C, Coronal section through the optic tract, at the level of the LGN, reacted to demonstrate HRP in order to reveal the injection site that labeled the retinas in $A$ and $B$. Note that there is no spread of HRP over the midline. Scale bar $=2 \mathrm{~mm}$. 


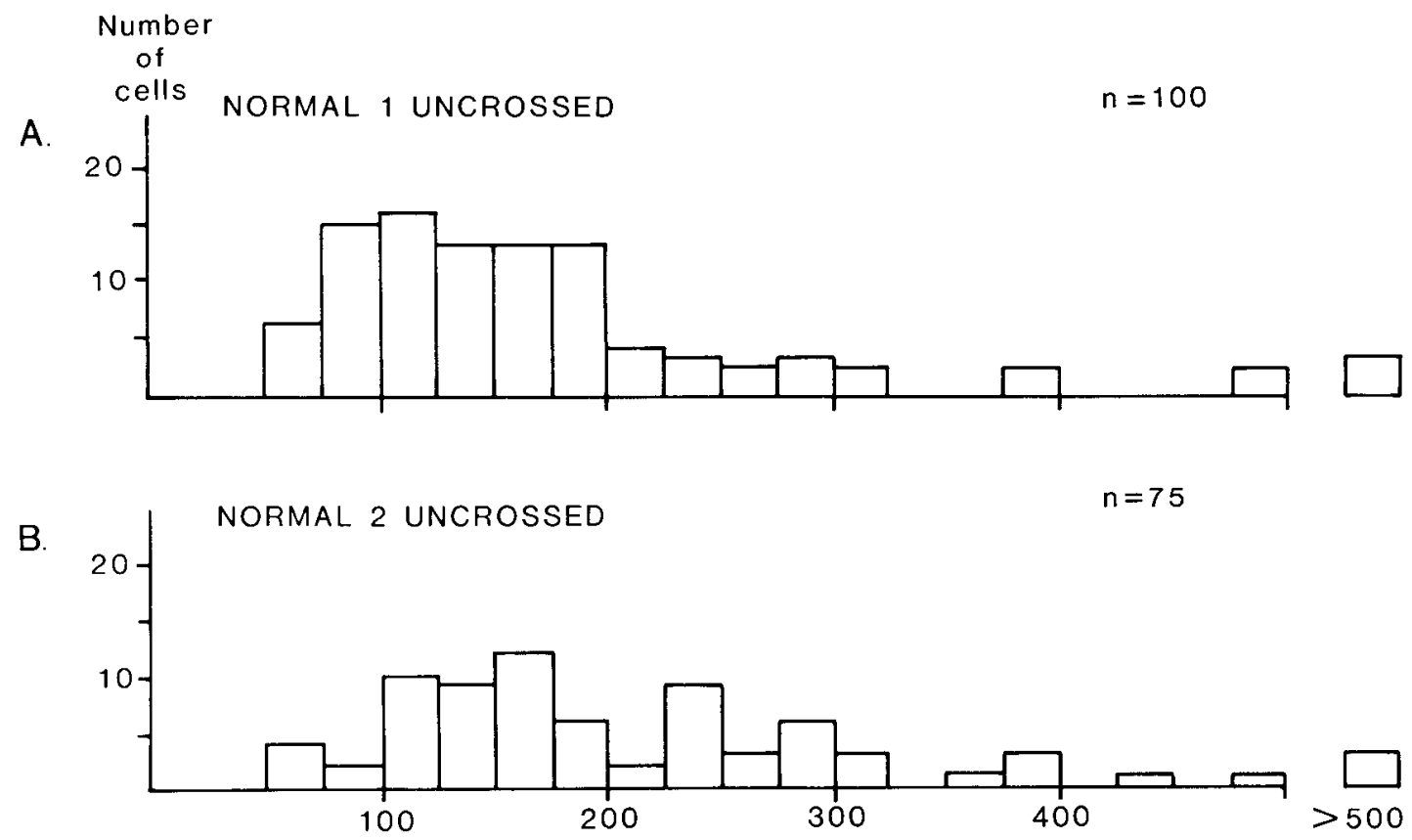

Figure 2. Histograms of all retinal ganglion cells, distributed by cell body area, participating in the uncrossed projection from the nasal retina in two normal adult cats. $A$, Cells with uncrossed projection from nasal retina of Normal Adult $1 . B$, Cells with uncrossed projection from nasal retina of Normal Adult 2. Abscissa, cell ared in syuare micrometers.

injections, except that the fixative used was $4 \%$ paraformaldehyde in $0.1 \mathrm{M}$ phosphate buffer, $\mathrm{pH} 7.2$, the eyes were enucleated after perfusion with fixative was finished, and the retinas were not postfixed. After HRP histochemistry the retinas were mounted immediately in phosphate buffer on clean slides. A UV source filtered with a Zeiss blueviolet BP 400 to $440 \mathrm{~nm}$ filter system was used for fluorescence microscopy. An extra series of brain sections was retained, mounted, air-dried, coverslipped with phosphate buffer, and examined to locate the FB deposits.

\section{Results}

The uncrossed projection from the nasal retina in the adult cat. Injection of HRP into one optic tract in the adult cat labels cells with a crossed projection in the retina contralateral to the injection (crossed cells) (Fig. 1A) and labels cells with an uncrossed projection in the eye ipsilateral to the injection (uncrossed cells) (Fig. 1B). As reported in the earlier studies of others (Stone, 1966; Wässle and Illing, 1980; Illing and Wässle, 1981), the uncrossed projection appears to arise almost exclusively from the temporal retina, whereas no such precise boundary exists for the crossed cells.

An injection was deemed adequate to fill the entire uncrossed projection from the nasal retina only if there was uniform filling of cell bodies along the inferior-superior and mediolateral extent of the ipsilateral temporal hemiretina and if there were labeled gamma cells distributed over the entire area of the contralateral temporal retina. The presence of labeled gamma cells in the contralateral temporal retina provides one means of verifying that the optic tract below the LGN has taken up HRP, because gamma cells that cross from the temporal retina project only to the superior colliculus (Illing and Wässle, 1981), and thus would not be filled if there was no uptake in the tract. The retinas from the two normal adult cats met these criteria.

The brains, which had been sectioned and reacted to demonstrate HRP, were examined to verify that there was no spread of HRP across the midline (Fig. $1 C$ ). In neither case did the spread within the hemisphere injected extend as far caudal as the superior colliculus.

Although the cells with uncrossed projection appear to be limited to the temporal retina, systematic scanning of the nasal retina of the eye ipsilateral to the injection revealed that, in fact, there was a small population of cells that project ipsilaterally from the nasal retina. In the two adult animals examined there were 75 and 100 of these cells, respectively. These cells were not different from the labeled ganglion cells in the temporal retina, as far as reaction product is concerned, and were distributed across the entire nasal retina with no apparent concentration in any region of the retina.

Ganglion cells in the adult cat, labeled to demonstrate HRP as described under "Materials and Methods," had a brownblack granular precipitate in the cytoplasm. Usually this precipitate was so dense that the nucleus was obscured. The dendrites were filled to a variable degree depending on the cell type and the degree of correspondence between the location in the retina and the topographic position of the injection site in the tract and LGN. Even though many cells appeared entirely filled, we considered any cell with a granular precipitate in the cytoplasm to be labeled and, thus, to project to the hemisphere injected.

The majority of cells in the nasal retina which project ipsilaterally have small cell bodies (area $<250 \mu \mathrm{m}^{2}$, Fig. 2) and dendritic trees comprised of fine, sparsely branched processes typical of gamma cells (Boycott and Wässle, 1974). The few cell bodies of medium size (Fig. 2) have sparse and extended dendritic trees typical of epsilon cells (Leventhal et al., 1980) or gamma cells of medium soma size (Stone and Clarke, 1980).

The uncrossed projection from the nasal retina during postnatal development. The retinal origins of the crossed and uncrossed projections in the newborn (P1) kitten have the same general appearance as those of the adult cat (Fig. $3, A$ and $B$, in comparison with Fig. $1, A$ and $B$ ). Figure $3, A$ and $B$, shows that the crossed projection extends across the temporal retina with the highest density of cells along the horizontal meridian. Even in the newborn kitten the uncrossed projection appears to have a precise boundary through the area centralis. Systematic scanning reveals a small population of labeled cells in the nasal retina, just as seen in the adult. However, the number of cells in the nasal retina of the P1 kitten is up to 6 times greater. Figure 4 shows the distribution of all of the HRPlabeled cells in the nasal retina of $\mathrm{P} 1, \mathrm{P} 4$, and $\mathrm{P} 10$ kittens and an adult cat. It is clear that there is a reduction in the popula- 

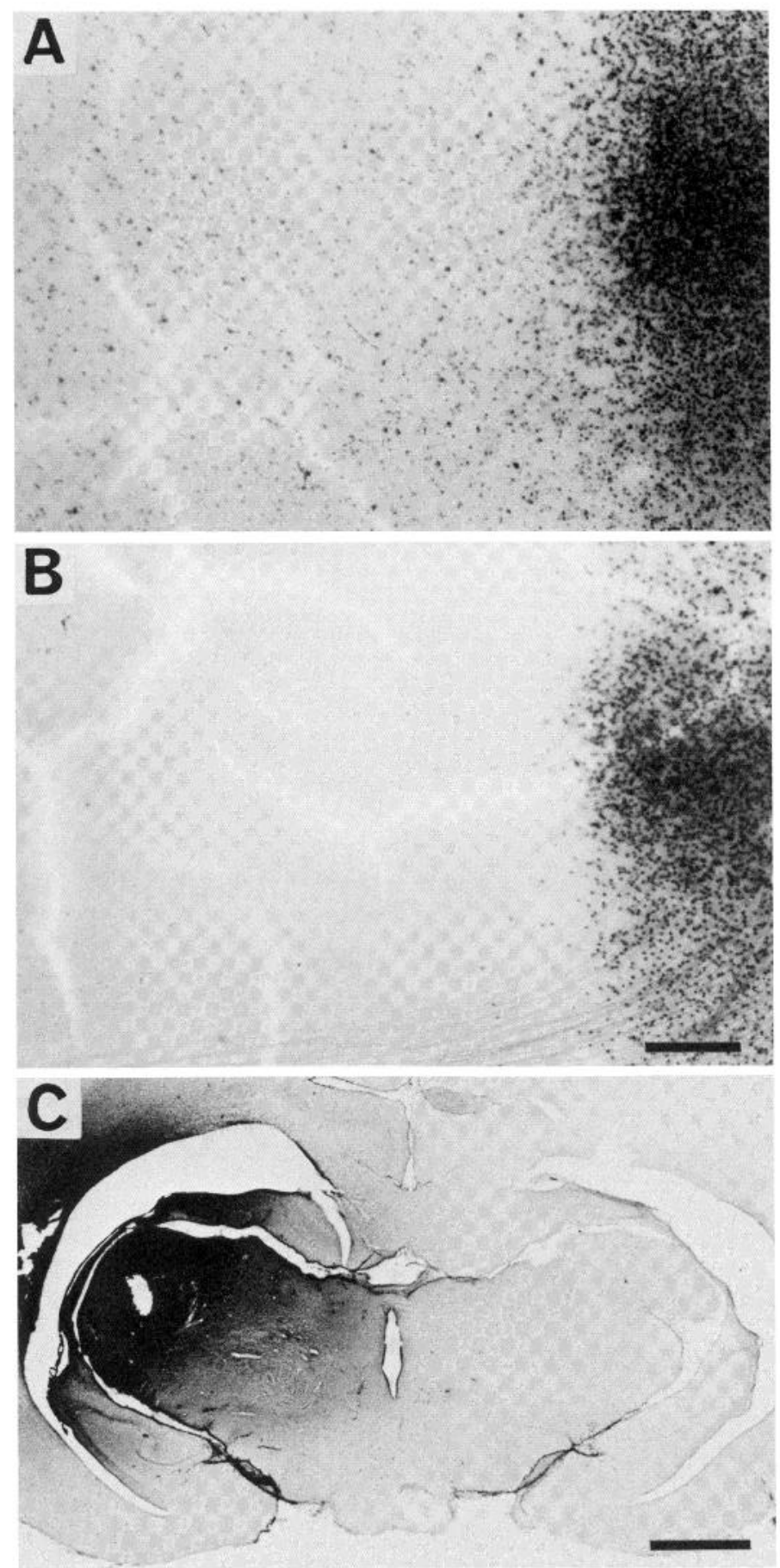

Figure 3. The retinal borders of the crossed and uncrossed projections to the brain in the P1 kitten. Other details are the same as for Figure 1. A, The retinal extent of the crossed projection in the P1 kitten. $B$, The retinal extent of the uncrossed projection in the P1 kitten. Scale bar (as in the adult) $=250 \mu \mathrm{m}$. $C$, Coronal section through the optic tract, at the level of the LGN, reacted to demonstrate HRP in order to reveal the injection site that labeled the retinas in $A$ and $B$. Note that the spread of HRP is confined to one hemisphere and that the injection site appears comparable to that in the adult (Fig. 1C). Scale bar $=2 \mathrm{~mm}$

Figure 4. Plots of the cells of the nasal retina with an uncrossed projection to the brain, as revealed by the retrograde transport of HRP, in kittens at P1, P4, and P10 and in the adult. The black area is the region of temporal retina where there is a high density of uncrossed
P1

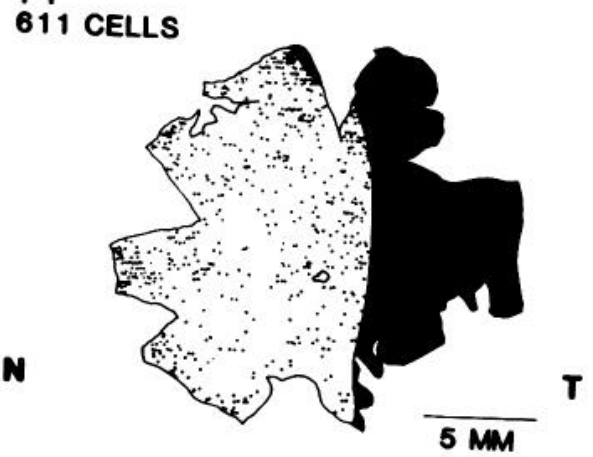

P4

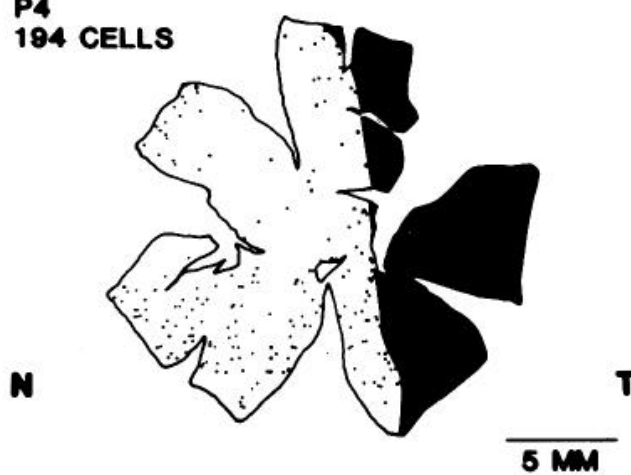

P10

155 CELLS

$\mathbf{N}$
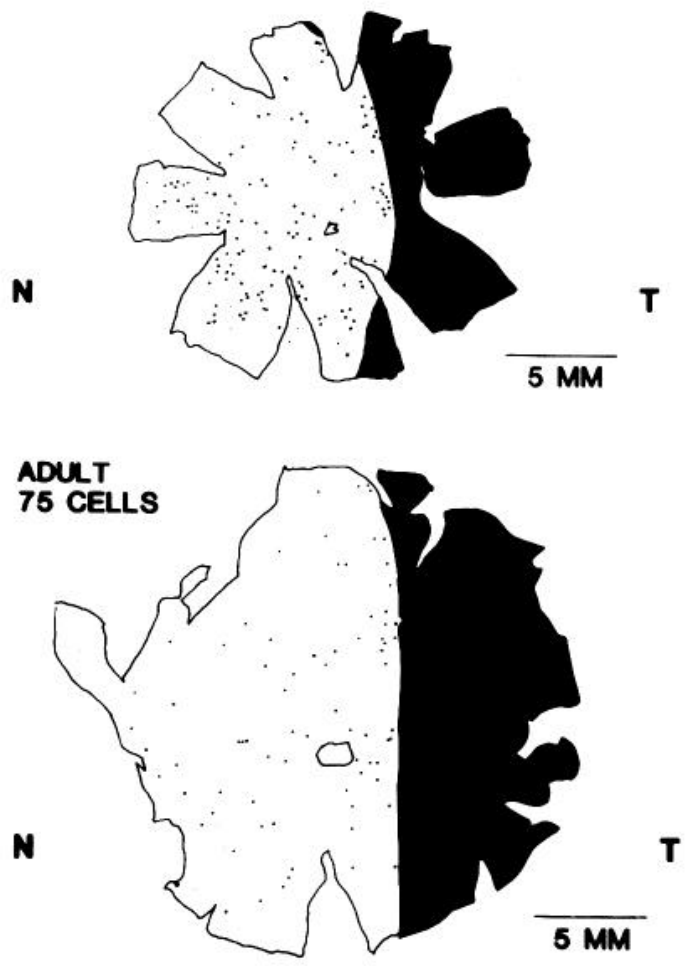

cells. At the nasal edge of this region there is a sudden drop in labeled cell density (Figs. $1 B$ and $3 B$ ). No cell in the nasal retina within 120 $\mu \mathrm{m}$ of this boundary was included in the plot. Shrinkage from processing was no more than $15 \%$ in any of these retinas. 


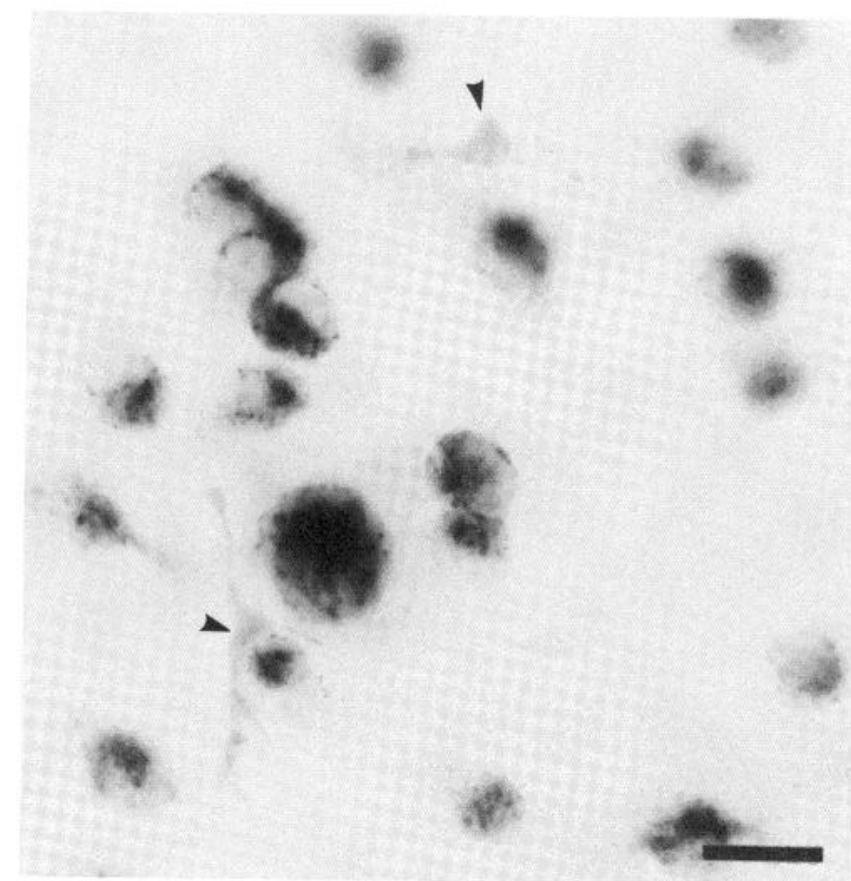

Figure 5. Pale, diffusely labeled cells (arrowheads) in the temporal retina ipsilateral to an injection of HRP in the P10 kitten. These cells have morphology that is not characteristic of ganglion cells and would not be counted as ganglion cells in plots of the nasal retinas. Scale bar $=20 \mu \mathrm{m}$.

tion during the first 10 days after birth. The entire nasal retinas of the four retinas shown in Figure 4 were intact to the peripheral border and therefore allow comparison of total cell numbers. In addition to the three intact kitten retinas, there were an additional three in which a large portion of the nasal retina was intact but not completely so.

One of these retinas was from a P1 kitten; it had 214 cells in the intact portion of the nasal retina, which amounted to $75 \%$ of the area of the nasal retina of the P1 kitten shown in Figure 4. Even casual inspection of the P1 retina shown in Figure 4 indicates that the greatest number of uncrossed nasal cells is located in the far periphery of the retina. Pieces from exactly this area were lost in the dissection of the second P1 kitten retina. The lack of intact peripheral retina in all likelihood accounts for the proportionally smaller number of labeled cells. Even if this were not the case, it is clear that the population of uncrossed cells in the nasal retina of the kitten is considerably larger than the population in the adult. There were also two retinas from $\mathrm{P} 4$ kittens that were about $90 \%$ intact and had 145 and 152 cells, respectively. Again, the lost part of retina was from the far periphery.

We think that it is unlikely that the decrease in number is due to a decrease in spread of HRP across the midline during development. Histological examination of coronal sections at the level of the injection site failed to show any reaction product over the midline in any of the kittens or cats. Figure $3 C$ is a photograph of a section through the injection site of the brain of the kitten from which the retinas in Figure $3, A$ and $B$, were taken. Comparison of a section of the injection site in one of the adult cats (Fig. $1 C$ ) with that shown in Figure $3 C$ indicates that the injection sites were of comparable extent and that there was no spread over the midline. In fact, even on the side ipsilateral to the tract injection, none of the animals (six total) in which the uncrossed population from the nasal retina was quantified showed spread of label as far caudal as the superior colliculus. Of the nine kittens in the developmental series, two had injections that failed to fill any ganglion cells. Histological examination of brain sections indicated that the injection site was inappropriately located, in that it did not pass through the LGN or penetrate the tract, but the spread of HRP was of the same extent as for injection sites in those kittens which had well filled ganglion cells. Again, this suggests that differential spread of HRP with age is not the reason more cells are labeled in the kitten. The ninth kitten had an injection site that was a partial "hit;" unfortunately the corresponding part of the nasal retina was poorly dissected, so that the number of labeled ganglion cells was not quantified.

The lack of labeled cells in the retinas of the kittens with injection sites that were "misses" indicates that we are using appropriate criteria to identify labeled ganglion cells in the kitten. An interesting feature of the kitten retinas was the appearance of a few cells with a pale diffuse reaction product and no granules. These cells did not have the morphology of ganglion cells, and characteristically they had a small cell body containing very little cytoplasm and a small nuclear profile. These cells often had one, two, or three elongated processes with varicosities along the length or at the end of each process (see Fig. 5). These cells are similar in morphology to macrophages recently described in the developing rodent retina

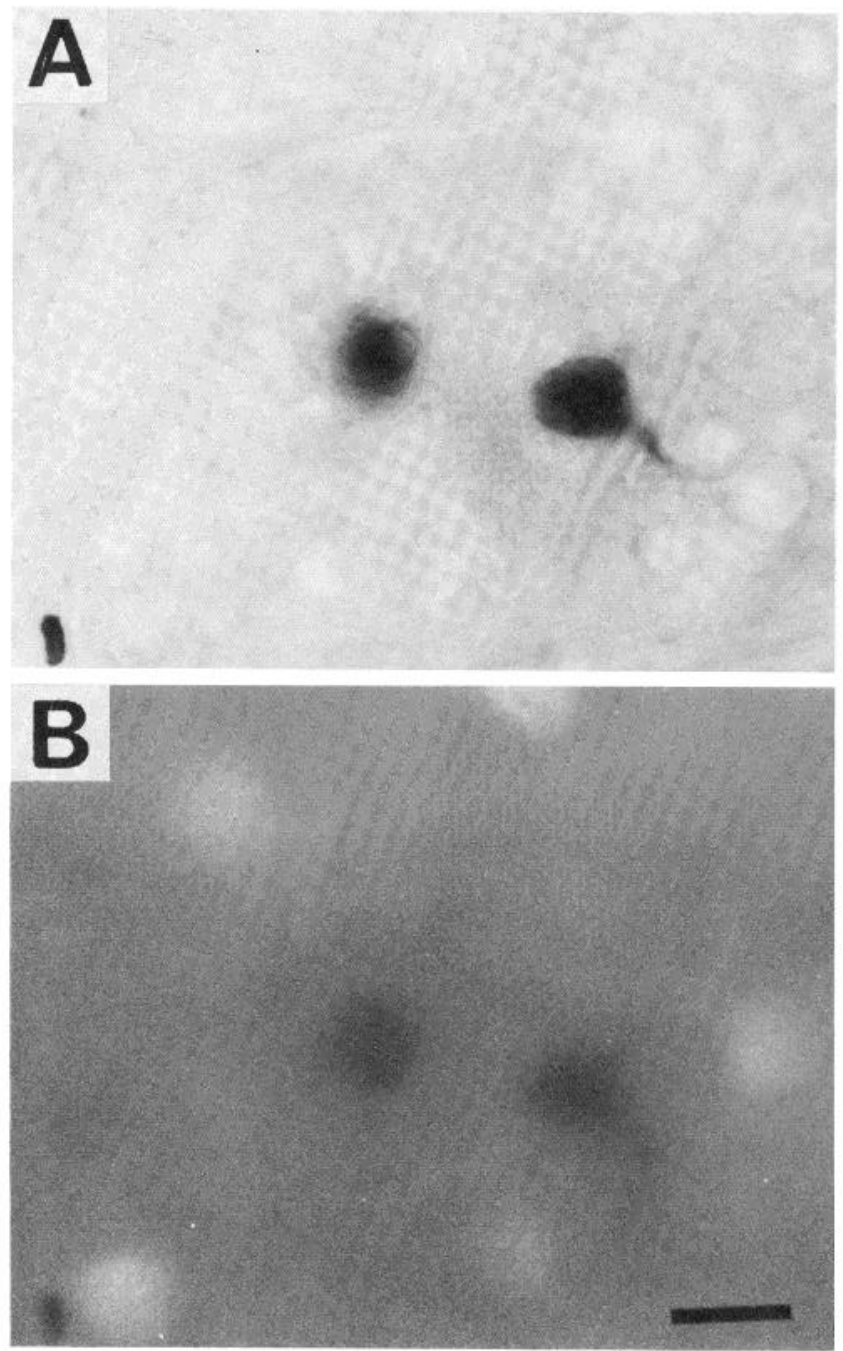

Figure 6. Micrographs of the nasal retina from an eye ipsilateral to an HRP injection and contralateral to an FB injection at P2. $A$, Brightfield micrograph. $B$, Fluorescence micrograph of the same field. Note that no cell contains both labels. Scale bar $=20 \mu \mathrm{m}$. 

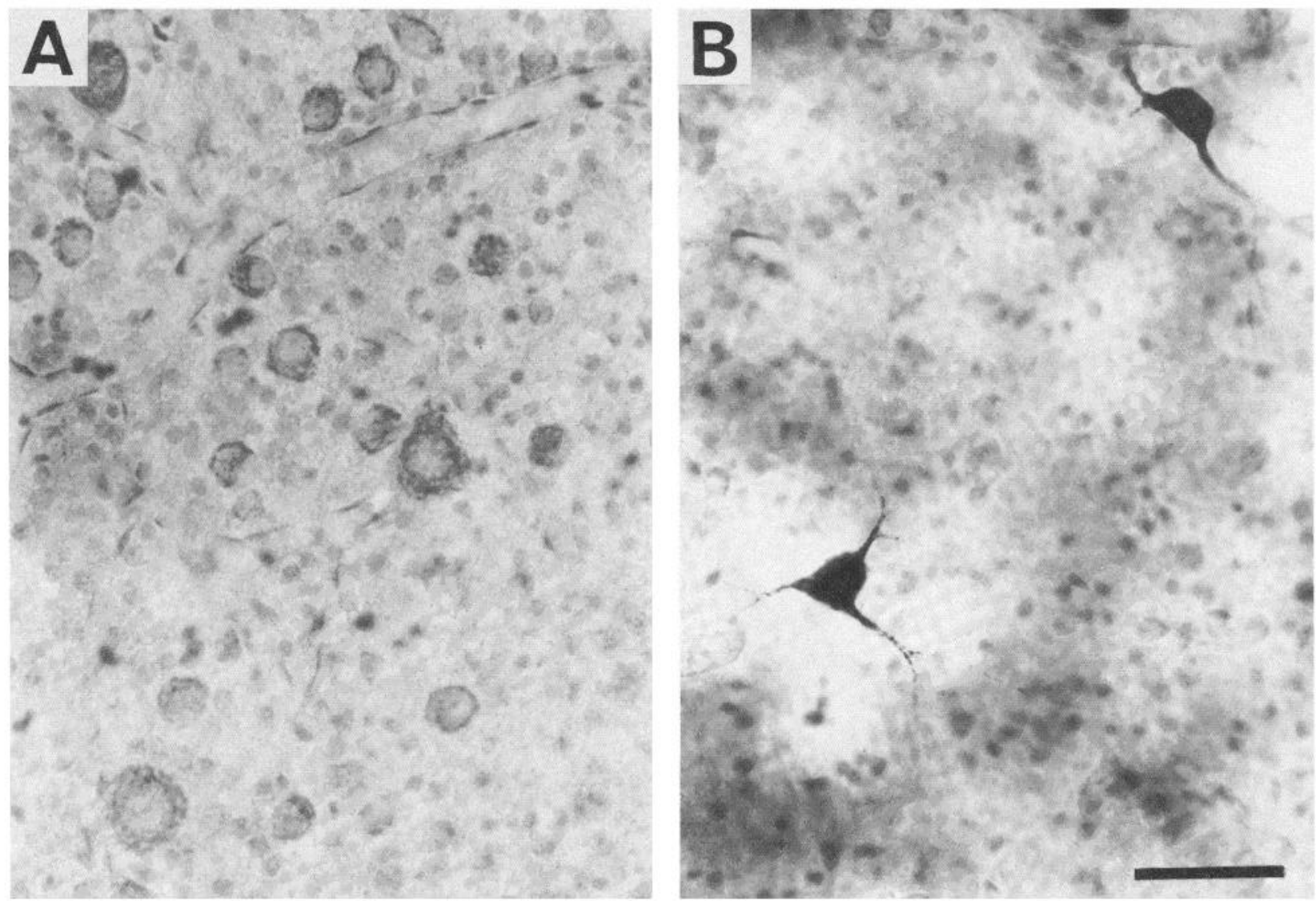

Figure 7. Fields from the spared and depleted regions of the nasal retina from an eye contralateral to a P1 tract lesion and ipsilateral to an HRP injection (from the retina shown in Fig. $8 A$ ). This retina has been counterstained with cresyl violet to reveal the ganglion cells that project through the tract that was not injected with HRP, to the hemisphere in which a lesion was made at P1. $A$, Micrograph of a field in the spared region. $B$, Micrograph of a field in the depleted region. This field contains two labeled cells that contribute to the increased uncrossed projection from the nasal retina in cats with a tract lesion. These micrographs were taken of fields $1 \mathrm{~mm}$ nasal to the optic disk and $2.5 \mathrm{~mm}$ into the superior $(A)$ and inferior $(B)$ retina. Scale bar $=50 \mu \mathrm{m}$.

(Hume et al., 1983; Perry et al., 1983) and were not counted as labeled ganglion cells.

In addition to determining the number of labeled cells, we carefully examined the cells in an attempt to ascertain whether a particular class is predominant in this population. Although the dendritic trees were not sufficiently filled with HRP to distinguish cell type, we found that most of the cell bodies were in the small to medium size range; large cells were rare.

Double label experiments. The HRP reaction product in these retinas was much the same as that described above. The FB yields pale diffuse fluorescence in the cytoplasm with some cells also having fluorescent granules in the cytoplasm as well. Jeffery et al. (1981) have previously demonstrated that both tracers can be visualized in the same cell. However, we did not observe any double-labeled cells in the eight retinas examined, even though HRP and FB could be seen in neighboring cells (Fig. 6) indicating that retinotopically corresponding points had been injected in the two optic tracts.

In two of the four animals, we counted the number of HRPlabeled cells in the nasal retina ipsilateral to the HRP injections. In one P1 retina we found 101 cells and in one P2 retina, 166 cells; of these 267 cells none were double labeled although surrounding cells were clearly labeled with FB. Although the number of cells filled in the nasal retina was somewhat less than the number found in the experiments described earlier, this can almost certainly be attributed to the fact that the high concentration of paraformaldehyde, required in the fixative for fluorescence microscopy, reduces the activity of HRP (Adams, 1977).

Neonatal tract lesion. One factor that might be important in mediating the elimination of inappropriate retinal projections is competition at the retinal level. We therefore attempted to deplete the nasal retina of the majority of ganglion cells by making unilateral tract lesions in five neonatal kittens. When the kittens were mature, injections of HRP were made into the optic tract that had not received a lesion. Two cats had injections that were adequate to label the entire uncrossed projection according to the criteria described earlier. Counterstaining with cresyl violet revealed that approximately half of each hemiretina (nasal in the eye contralateral to the lesion, temporal in the ipsilateral eye) had been virtually depleted of ganglion cells as a result of the lesion. Except for the lack of ganglion cell profiles, the depleted region seemed normal and no different from the portion of nasal retina not depleted of ganglion cells. Areas of retina representative of the spared and depleted regions are shown in Figure 7.

The total number of labeled cells in the nasal hemiretinas of the cats that had received a lesion was greater than the total found in the normal adult. Ipsilaterally projecting cells were more numerous in the region that had been most severely depleted of contralaterally projecting ganglion cells (see Fig. 8). These two cats had 236 and 204 uncrossed cells in the nasal retina, and whereas the depleted regions comprised only $56 \%$ and $49 \%$ of the area of the nasal retina, they contained $70 \%$ 
A

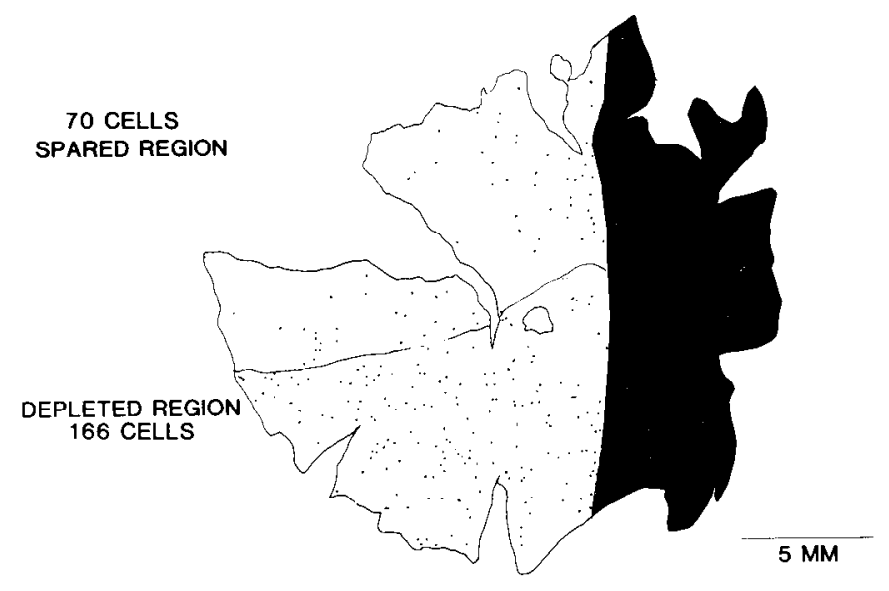

B

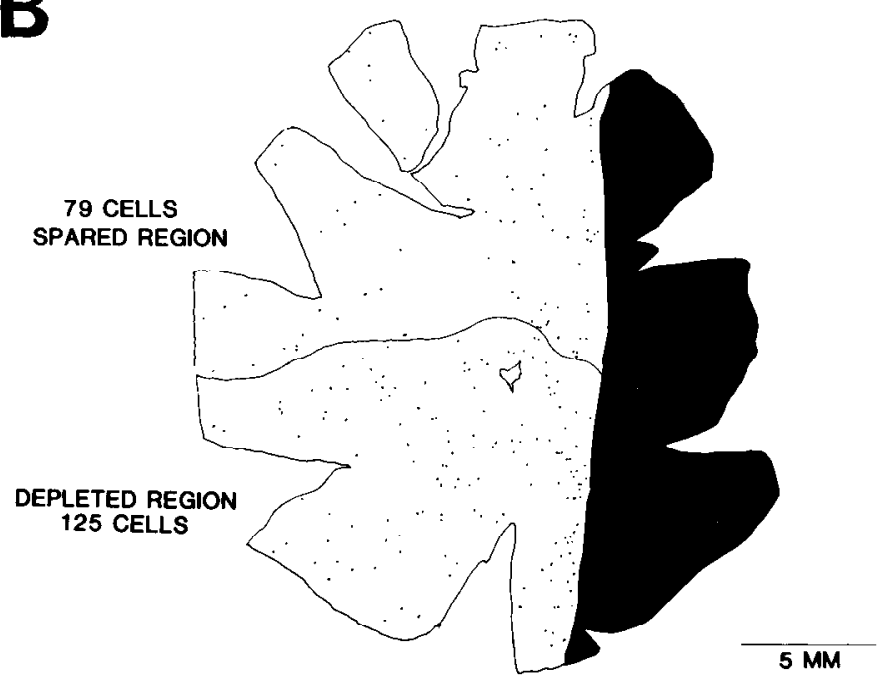

Figure 8. Plots of two retinas from cats that had undergone an optic tract lesion at P1. These retinas are both ipsilateral to an injection of HRP and contralateral to the lesion. The line across the nasal hemiretina indicates the border along which there is a sudden increase in ganglion cell density. The spared and depleted regions are labeled on either side of the line. The numbers of uncrossed cells in the depleted and spared regions are also given. Shrinkage in these two retinas was less than $20 \%$.

and $61 \%$ of the uncrossed cells, respectively. The line across the nasal retina (in Fig. 8) was drawn through the zone of maximum change in density of cresyl violet-stained ganglion cells. Two millimeters above the transition zone, ganglion cell density was comparable to that at the same location in the retina of a normal cat.

Histograms of the sizes of the labeled cells in the spared and depleted regions of the retina shown in Figure $8 A$ are presented in Figure 9. The soma size distribution of the uncrossed cells from the depleted region is significantly different on a $\chi^{2}$ test (Siegel, 1956) from the distributions of the populations of uncrossed cells from the nasal retina of two normal cats $\left(\chi^{2}=\right.$ $49.2,19.0 ; d f=7 ; p<0.001$ ), whereas the soma size distribution of the uncrossed cells from the spared region is not $\left(\chi^{2}=10.5\right.$,
$11.3 ; d f=7 ; 0.20>p>0.10$ for both populations). As inspection of Figure 9 shows, the population from the depleted region has a clear excess of cells in the small to medium size range, in comparison with the population from the spared region. The spared region serves as a good control, as differences, both in tissue processing and between animals, need not be considered.

In the cats that received a lesion, the majority of the uncrossed cells, of the cells in the nasal retina that were identifiable, were of the gamma class, as indicated by their small cell bodies and extended, sparsely branched dendritic trees. The cells of medium size had cell body profiles of fusiform or angular shape, stout primary dendrites, and sparsely branched, extended dendritic trees. The effect of the lesion was thus to increase the number of gamma and epsilon cells with uncrossed projection in the nasal retina, without causing the same effect on alpha and beta cells.

We have examined the dendritic morphology of cells along the border between the intact ipsilateral projection and the depleted nasal retina, to determine whether the absence of cells in the nasal retina had any influence on the orientation of the dendrites. In the normal cat the dendrites of beta cells located along the border show no preferred orientation. However, in the operated cats, beta cells on the border, that had close neighbors on their temporal side but not on their nasal side, showed a tendency for the dendrites to be directed toward the depleted nasal retina. Beta cells with few or no neighbors showed no preferred orientation. This tendency for an asymmetry in beta cell dendrites was not seen in the other cell types and was not as conspicuous as that found in the rat after neonatal retinal lesions (Perry and Linden, 1982). The dendrites of cells with few or no neighbors appeared to be restricted to a sublamina within the inner plexiform layer, as is seen in the normal cat.

\section{Discussion}

We have found that there are more than 600 cells in the nasal retina of the newborn kitten with an ipsilateral projection to the brain. The size of this population is reduced to onefourth of that value by P10; the two adult cats examined had 75 and 100 of these cells. We can "rescue" some of these cells by making a lesion, at $\mathrm{P} 1$, in the contralateral optic tract, which depletes much of the nasal retina of ganglion cells and presumably allows the exuberant projection of the kitten to survive. The projections that are rescued belong to cells of the gamma and epsilon classes but not to the alpha and beta classes.

Stone et al. (1978) and Cooper and Pettigrew (1979a, b) found no evidence for an uncrossed projection from the nasal retina of normal cats. Subsequent investigators have reported that only small cells (Wässle and Illing, 1980); gamma, g1, g2, and epsilon cells (Leventhal, 1982); and gamma and alpha cells (Murakami et al., 1982) participate in the uncrossed projection from the nasal retina. Wässle and Illing (1980) reported that these cells have a density of less than $1 / \mathrm{mm}^{2}$, and the report of Murakami et al. (1982) shows less than 60 of these cells.

The fact that our findings regarding the general magnitude of the projection, and the morphological types participating in it, are in accord with previous results, coupled with the fact that no other study reports more of these cells, indicates that we have, in all likelihood, labeled the entire projection in the adult.

It is probable that the precision of the nasotemporal divide is not completely determined during the initial sequence of axon outgrowth and location of a terminal target structure. To obtain the characteristic adult boundary seems to require an elimination of inappropriate projections; that is, elimination of the majority of the ipsilateral projection from the ganglion cells in the nasal retina in the newborn kitten. We do not know 


$$
\begin{gathered}
\text { Number } \\
\text { of } \\
\text { cells }
\end{gathered}
$$

A.

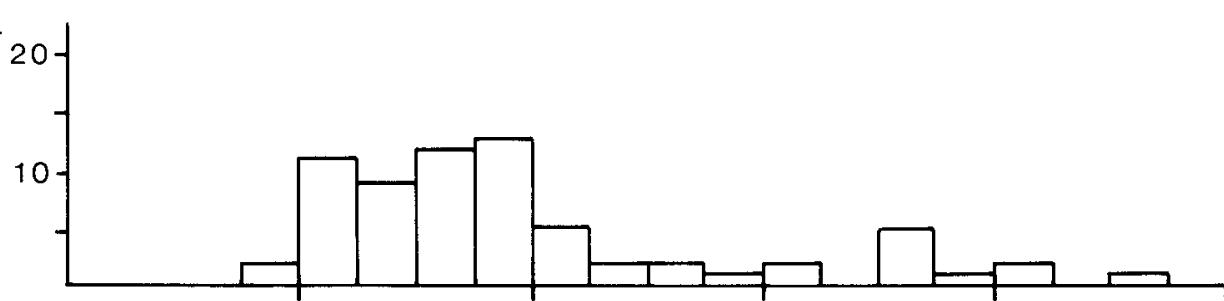

$n=70$

\section{DEPLETED REGION}

$n=166$

\section{B}

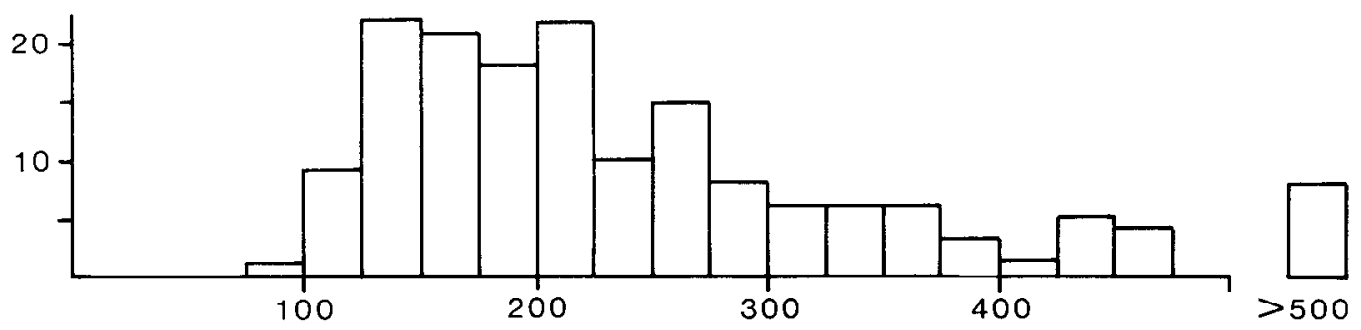

Figure 9. Histograms of the labeled retinal ganglion cells, distributed by cell body area, from the spared $(A)$ and depleted $(B)$ regions of the retina in Figure 8A. Abscissa, cell area in square micrometers.

whether this elimination proceeds by the loss of an inappropriate axon collateral or degeneration of the cell body. Although elimination of axon collaterals plays an important role in refining the precision of some projections, for example the interhemispheric cortical projections via the corpus callosum (Innocenti, 1981; O'Leary et al., 1981), there is also evidence of cell death playing a role in the normal development of the cat retina ( $\mathrm{Ng}$ and Stone, 1982; Stone et al., 1982; Williams et al., 1983). In rodents there is some evidence for bifurcating ganglion cells projecting to both hemispheres, although their numbers are very small (Jeffery et al., 1981; Jeffery and Perry, 1982; Insausti et al., 1984). Earlier suggestions of large numbers of ganglion cells with bifurcating axons (Cunningham, 1976; Cunningham and Freeman, 1977) have subsequently been shown to be incorrect, and the reasons have been discussed by Jeffery et al. (1981).

We used the double label technique in an attempt to determine whether the ipsilaterally projecting ganglion cells located in the nasal retina of the neonatal kitten have bifurcating axons. Although our study did not produce evidence for bifurcating axons in the kitten, a result consistent with the evidence in the adult cat (Illing, 1980), the results were not conclusive because we could only demonstrate filling in a proportion of the ipsilaterally projecting ganglion cells of the nasal retina (see "Results" for discussion of method). In one kitten which was injected on P1 and which survived for $48 \mathrm{hr}$, we would have expected to find between 200 and 600 cells in the nasal retina which project ipsilaterally, but we only succeeded in labeling 100 cells. In the P2 kitten which survived $56 \mathrm{hr}$ we would have expected to find at least 200 such cells in the nasal retina, but we only found 166 . It is clearly possible that the cells we failed to label were indeed bifurcating ganglion cells. This caveat must also apply to the cells in the temporal retina for, although we did not find bifurcating cells, we did not quantify the number of labeled cells, and it is conceivable that some of the cells we failed to label had bifurcating axons.

In the depleted part of the nasal retina of a cat that had received a $\mathrm{P} 1$ tract lesion there are many more small and medium sized ganglion cells than in the normal adult. Although we did not fill the entire dendritic tree of every one of these cells, it was clear from the primary and secondary dendritic branching pattern that the cells of medium size were not beta cells; most of these cells had dendritic trees characteristic of epsilon cells (Leventhal et al., 1980). The small cells were gamma-like (Boycott and Wässle, 1974). The fact that we did not rescue a significant number of beta or alpha cells, which are generated prior to cells with small cell bodies (Walsh et al., 1983), suggests that there may be a phase of cell death or selective elimination of the inappropriate projections for each class of ganglion cell, the phases occurring in the same sequence as that in which the cell classes are generated.

It is quite possible that at the time in prenatal development when cells are sending their axons through the chiasm, there is a considerable population of ipsilaterally projecting cells in the nasal retina, and that we have observed only the end of the selective elimination which gives rise to the precise nasotemporal border of the uncrossed projection to the brain in the cat. It would be of considerable interest to know whether successively earlier lesions would rescue alpha and then beta cells projections.

\section{References}

Adams, J. C. (1977) Technical considerations on the use of horseradish peroxidase as a neuronal marker. Neuroscience $2: 141-145$.

Anker, R. L. (1977) The prenatal development of some of the visual pathways in the cat. J. Comp. Neurol. 173: 185-204.

Bentivoglio, M., H. G. J. M. Kuypers, C. E. Catsman-Berrevoets, H. Loewe, and O. Dann (1980) Two new fluorescent tracers which are transported over long distances. Neurosci. Lett. 18: 25-30.

Boycott, B. B., and H. Wässle (1974) The morphological types of ganglion cells of the domestic cat's retina. J. Physiol. (Lond.) 240: $397-419$.

Cleland, B. G., M. W. Dubin, and W. R. Levick (1971) Sustained and transient neurons in the cat's retina and lateral geniculate nucleus. J. Physiol. (Lond.) 217: 473-496.

Cooper, M. L., and J. D. Pettigrew (1979a) The decussation of the retinothalamic pathway in the cat, with a note on the major meridians of the cat's eyes. J. Comp. Neurol. 187: 285-312.

Cooper, M. L., and J. D. Pettigrew (1979b) The retinothalamic path- 
ways in Siamese cats. J. Comp. Neurol. 187: 313-348.

Cunningham, T. J. (1976) Early eye removal produces excessive bilateral branching in the rat: Application of cobalt filling method. Science 194: 857-859.

Cunningham, T. J., and J. A. Freeman (1977) Bilateral ganglion cell branches in the normal rat. A demonstration with electrophysiological collision and cobalt tracing methods. J. Comp. Neurol. 172: 165176.

Eldridge, J. L., Z. Henderson, and V. C. Wilkins (1981) A stereotaxic method for neonatal kitten brain. J. Physiol. (Lond.) 320: 12P.

Enroth-Cugell, C., and J. G. Robson (1966) The contrast sensitivity of retinal ganglion cells in the cat. J. Physiol. (Lond.) 187: 517-552.

Fukuda, Y., and J. Stone (1974) Retinal distribution and central projections of W-, X-, and Y-cells of the cat's retina. J. Neurophysiol. 37: $749-772$.

Hume, D. A., V. H. Pcrry, and S. Gordon (1983) Immunohistochemical localisation of a macrophage specific antigen in developing mouse retina. Phagocytosis of dying neurons and differentiation of microglial cells to form a regular array in the plexiform layers. J. Cell Biol. 97: 253-257.

Illing, R. -B. (1980) Axonal bifurcation of cat retinal ganglion cells as demonstrated by retrograde double labelling with fluorescent dyes Neurosci. Lett. 19: 125-130.

Illing, R. -B., and H. Wässle (1981) The retinal projection to the thalamus in the cat: A quantitative investigation and a comparison with the retinotectal pathway. J. Comp. Neurol. 202: 265-285.

Innocenti, G. M. (1981) Growth and reshaping of axons in the establishment of visual callosal connections. Science 212: 824-827.

Insausti, R., C. Blakemore, and M. W. Cowan (1984) Ganglion cell death during development of ipsilateral retino-collicular projection in golden hamster. Nature 308: $362-365$.

Jacobs, D. S., and V. H. Perry (1983) Postnatal development of the uncrossed retinal projection in the cat. J. Physiol. (Lond.) 345: 41P.

Jeffery, G., and V. H. Perry (1982) Evidence for ganglion cell death during development of the ipsilateral retinal projection in the rat Dev. Brain Res. 2: 176-180.

Jeffery, G., A. Cowey, and H. G. J. M. Kuypers (1981) Bifurcating retinal ganglion cell axons in the rat, demonstrated by retrograde double labelling. Exp. Brain Res. 44: 34-40.

Kirk, D. L., W. R. Levick, and B. G. Cleland (1976a) The crossed or uncrossed destination of axons of sluggish-concentric and non-concentric cat retinal ganglion cells, with an overall synthesis of the visual field representation. Vision Res. 16: 233-236.

Kirk, D. L., W. R. Levick, B. G. Cleland, and H. Wässle (1976b) Crossed and uncrossed representation of the visual field by brisksustained and brisk-transient cat retinal ganglion cells. Vision Res. 16: $225-231$.

Leventhal, A. G. (1982) Morphology and distribution of retinal ganglion cells projecting to different layers of the dorsal lateral geniculate nucleus in normal and Siamese cats. J. Neurosci. 2: 1024-1042.

Leventhal, A. G., J. Keens, and J. Tork (1980) The afferent ganglion cells and cortical projections of the retinal recipient zone of the cat's pulvinar complex. J. Comp. Neurol. 194: 535-554

Murakami, D., M. A. Sesma, and M. H. Rowe (1982) Characteristics of nasal and temporal retina in Siamese and normally pigmented cats. Brain Behav. Evol. 21: 67-113.
Ng, A. Y. K., and J. Stone (1982) The optic nerve of the cat: Appearance and loss of axons during normal development. Dev. Brain Res. 5: 263-271.

O'Leary, D. D. M., B. B. Stanfield, and W. M. Cowan (1981) Evidence that the early postnatal restriction of the cells of origin of the callosal projection is due to the elimination of axonal collaterals other than to the death of neurons. Dev. Brain Res. 1: 607-617.

Perry, V. H., and R. Linden (1982) Evidence for dendritic competition in the developing retina. Nature 297: 683-685.

Perry, V. H., Z. Henderson, and R. Linden (1983) Postnatal changes in retinal ganglion cell and optic axon populations in the pigmented rat. J. Comp. Neurol. 219: 356-368.

Polyak, S. (1957) The Vertebrate Visual System, University of Chicago Press, Chicago.

Rose, G. H., and E. F. Goodfellow (1973) A Stereotaxic Atlas of the Kitten Brain, Brain Information Service/Brain Research Institute, University of California, Los Angeles.

Sanderson, K. J. (1971) The projection of the visual field to lateral geniculate and medial interlaminar nuclei in the cat. J. Comp. Neurol. 143: 101-118.

Shatz, C. J. (1983) The prenatal development of the cat's retinogeniculate pathway. J. Neurosci. 3: 482-499.

Siegel, S. (1956) Nonparametric Statistics for the Behavioral Sciences, McGraw-Hill Book Co., Inc., New York.

Stone, J. (1966) The nasotemporal division of the cat's retina. J. Comp. Neurol. 126: 585-600.

Stone, J., and C. Clarke (1980) Correlation between soma size and dendritic morphology in cat retinal ganglion cells. Evidence for further variation in the gamma-cell class. J. Comp. Neurol. 192: 211218.

Stone, J., and Y. Fukuda (1974) The naso-temporal division of the cat's retina re-examined in terms of W-, X-, and Y-cells. J. Comp. Neurol. 155: 377-394.

Stone, J., and K. -P. Hoffman (1972) Very slow-conducting ganglion cells in the cat's retina: A major new functional type? Brain Res. 43: 610-616.

Stone, J., J. E. Campion, and J. Leicester (1978) The nasotemporal division of retina in the Siamese cat. J. Comp. Neurol. 180: 783-798.

Stone, J., D. H. Rapaport, R. W. Williams, and L. Chalupa (1982) Uniformity of cell distribution in the ganglion cell layer of prenatal cat retina: Implications for mechanisms of retinal development. Dev. Brain Res. 2: 231-242.

Torrealba, F., R. W. Guillery, U. Eysel, E. H. Polley, and C. A. Mason (1982) Studies of retinal representations within the cat's optic tract. J. Comp. Neurol. 211: 377-396.

Walls, G. L. (1942) The Vertebrate Eye, Hafner, New York.

Walsh, C., E. H. Polley, T. L. Hickey, and R. W. Guillery (1983) Generation of cat's retinal ganglion cells in relation to central pathways. Nature 302: 611-614.

Wässle, H., and R. -B. Illing (1980) The retinal projection to the superior colliculus in the cat: A quantitative study with HRP. J. Comp. Neurol. 190: 333-356.

Williams, R. W., M. J. Bastiani, and L. M. Chalupa (1983) Addition and attrition of axons in the optic nerve during the ontogeny of the cat: The appearance of growth cones and necrotic axons. Invest. Ophthalmol. Vis. Sci. (Suppl.) 24: 8. 